\title{
When humoral became cellular
}

In his seminal contribution to clonal selection theory, Australian Nobel laureate Sir Frank Macfarlane Burnet describes the trajectory of a scientific career in terms that could be applied to the timeline of these antibody milestones. He wrote “...we tend to move gradually, or on occasion precipitately, from one topic of interest to another....influenced by pressures from work done in a dozen different laboratories...."

In Burnet's case the laboratories were those around him at the Walter and Eliza Hall Institute in Melbourne, Australia, and the US laboratory of his peer David Talmage, which published in advance of Burnet's relatively obscure 1957 article in the Australian Journal of Science. Burnet's clonal selection theory extended the idea that each antibody-producing cell makes antibodies of only one specificity, predicting these cells proliferate in response to the detection of antigens, cloning and thus selectively increasing antibody abundance; hence, clonal selection. Although Talmage was first, crucially, and correctly,
Burnet also predicted that diversity of antibody specificities needs a cellular mechanism to randomize and create diversity. Subsequently, such randomization was shown to occur through somatic recombination and hypermutation (MILESTONE 10).

The clonal selection theory has its origins in Paul Ehrlich's visionary turn-of-the-19th-century 'side-chain theory of antibody production' (MILESTONE 2), but decades passed mired in 'direct template' theories, until Niels Jerne argued that antibody diversity is ready-made and awaits antigenic interaction rather than being a consequence of antigen exposure. This theory precipitated the concept of selection so acutely for Burnet that he entitled his paper "A modification of Jerne's theory of antibody production using the concept of clonal selection."

Wider influences on Burnet's version of clonal selection were emergent ideas about cancer mutation and in the established fields of bacteriology and virology. In the words of his student Gus Nossal, Burnet was

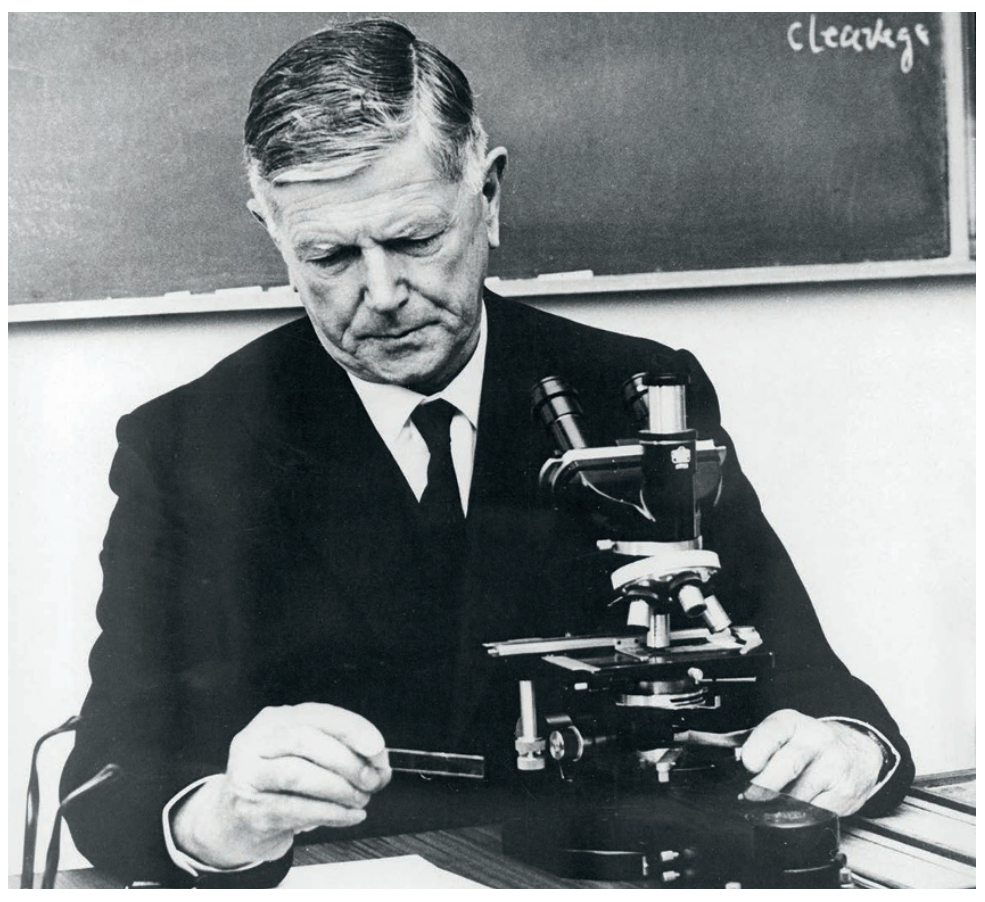

Sir Frank Macfarlane Burnet at the microscope, circa 1960, at The University of Melbourne, Australia. Image supplied with permission from the Walter and Eliza Hall Institute of Medical Research, Melbourne, Australia. ce

Burnet's

version of the

theory clearly

employs ideas

about clonal

outgrowth of

microbes and

somatically

mutated

cancer cells

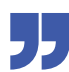

"Australia's greatest virologist," and indeed his theory employs ideas about the clonal outgrowth of microbes and somatically mutated cancer cells.

The first experimental evidence for Burnet's theory came from Gus Nossal and Joshua Lederberg; they stimulated rat cells with more than one antigen to find that only one antibody is subsequently detectable in the culture medium (MILESTONE 3). This effective monoclonal antibody production led to a series of papers providing more decisive evidence, as techniques matured, and ultimately to modern antibody technology (MILESTONES 9, 12). However, the implications of the clonal selection theory are broader than the obvious development of antibody technology. An attempt to understand antibody diversity led to better understanding of vaccinology, to the parallel concept of T cell clonal selection, and to Medawar and Burnet's Nobel Prize "for discovery of acquired immunological tolerance" and its implications for autoimmunity and cancer biology.

However, the greatest contribution of clonal selection theory was predicted by Burnet, who wrote that " $t$ ] he chief novelty of the clonal selection theory is its concentration, not on what happens in an individual cell, but on the way cell populations are modified by the presence of antigenic determinants in their environment of the body fluids." Indeed, the clonal selection theory has merged concepts of cell and humoral biology into the modern discipline of systemic immunology.

Nicholas J. Bernard, Associate Editor, Nature Communications
ORIGINAL RESEARCH PAPERS Burnet, F. M. The Clonal Selection Theory of Acquired Immunity (Cambridge University Press, Cambridge, UK, 1959) | Talmage, D. W. Allergy and immunology. Ann. Rev. Med. 8, 239-256 (1957)|Burnet, F. M. A modification of Jerne's theory of antibody production using the concept of clonal selection. Aust. J. Sci. 20, 67-69 (1957) | Tonegawa, S. Somatic generation of antibody diversity. Nature 302, 575-581 (1983) | Ehrlich, P. Croonian lecture: on immunity with special reference to cell life. Roy. Soc. Proc. London 66, 424-448 (1900) | Jerne, N. K. The natural selection theory of antibody formation. Proc. Natl. Acad. Sci. USA 41, 849-857 (1955) | Nossal, G. J. \& Lederberg, J. Antibody production by single cells. Nature 181, 1419-1420 (1958) FURTHER READING Hodgkin, P. D. et al. The clonal selection theory: 50 years since the revolution. Nat. Immunol. 8, 1019-1026 (2007) |Cohn, M. et al. Reflections on the clonalselection theory. Nat. Rev. Immunol. 7, 823-830 (2007)| Silverstein, A. M. A history of immunology. 2nd edn (Elsevier, 2009) | Nossal, G. J. One cell-one antibody: prelude and aftermath. Nat. Immunol. 8, 1015-1017 (2007) 